\title{
Pectoralis Major
}

National Cancer Institute

\section{Source}

National Cancer Institute. Pectoralis Major. NCI Thesaurus. Code C33284.

Either of two large, bilateral muscles overlying the upper, anterior chest wall, which has two heads: the clavicular head, which originates on the medial half of the clavicle, and the sternal head, which originates on the sternum and the first six costal cartilages; the muscles insert onto the lateral lip of the intertubercular groove of the humerus and the crest of the greater tubercle of the humerus respectively, and function to flex, adduct, and medially rotate the shoulder joint. 